\title{
Microangiopathic Hemolytic Anemia and Diffuse Bone Metastasis by Signet Ring Cell Adenocarcinoma
}

\author{
Andrés J. Muñoz Martín, Pilar García Alfonso, María Carmen Riesco Martínez, Virginia Martínez \\ Marín, Yolanda Jerez Gilarranz, Rebeca Mondejar Solís, Miguel Martín Jiménez
}

Medical Oncology Service, Hospital General Universitario “Gregorio Marañón”, Madrid, Spain.

Email: andresmunmar@hotmail.com

Received April 12 $2^{\text {th }}, 2010$; revised May 21 ${ }^{\text {st }}, 2010$; accepted June $7^{\text {th }}, 2010$.

\begin{abstract}
Microangiopathic hemolytic anemia (MAHA) is a rare paraneoplastic syndrome and is typically associated with gastric adenocarcinoma. We report a 47-year-old woman who presented with asthenia, lower back pain and bleeding. Twelve years ago the patient underwent total gastrectomy due to gastric adenocarcinoma and achieved complete remission. The patient was diagnosed with MAHA and diffuses bone metastasis of signet ring cell adenocarcinoma of unknown origin and was treated successfully with polichemotherapy based on cisplatin and 5-fluorouracil.
\end{abstract}

Keywords: Microangiopathic Haemolytic Anemia, Gastric Cancer, Paraneoplastic Syndrome, Chemotherapy, Signet Ring Cell Adenocarcinoma

\section{Introduction}

MAHA was first described in 1962 by Brain et al. [1] and is an uncommon haematological disorder which can appear in different diseases (thrombotic thrombocytopenic purpura, haemolytic ureamic syndrome, vasculitis and paraneoplastic syndrome in cancer) [2]. It is defined as a severe haemolytic anemia with negative Coombs test and fragmentation of red cells in the peripheral blood smear. MAHA occurs in patients with metastasized signet cell carcinoma of stomach but it's been described in breast and lung carcinoma [3]. The pathogenesis of cancer-related MAHA is not well understood. Typically, it's associated to diffuse bone metastasis by signet ring cell adenocarcinoma. MAHA can be the first manifestation of metastatic carcinoma and is associated to extremely poor prognosis $[4,5]$. Sometimes is the first sign of recurrence after a curative surgery even many years later [6,7].

In this report we describe the case of a 47-year-old woman with a medical history of gastric cancer twelve years ago who was diagnosed with MAHA and massive infiltration of bone marrow by signet cell carcinoma. After careful workup the primary site could not be identified. The patient responded dramatically to polichemotherapy and long-term partial response was achieved.

\section{Case Report}

A 47- year-old woman was referred to our service with a medical history of 8 months of lower back pain. During the last week she referred asthenia, vaginal bleeding, epistaxis and bulky bruises widespread. Twelve years ago the patient was diagnosed with gastric adenocarcinoma. She underwent total gastrectomy and achieved a R0 resection (pathological stage pT2pN0M0). No adjuvant treatment was delivered.

At the emergency room the patient showed pale skin, tachycardia at $110 \mathrm{bpm}$. No other relevant signs were found at physical examination, $\mathrm{ECOG}=3$. Laboratory work-up yielded the following results: haemoglobin 4,9 $\mathrm{g} / \mathrm{dL}$, white blood cells (WBC) $8,400 / \mu \mathrm{L}$ with $39,6 \%$ neutrophils and $36,2 \%$ lymphocytes, platelets $9.000 / \mu \mathrm{L}$, total bilirubin $2.1 \mathrm{mg} / \mathrm{dL}$, GOT $69 \mathrm{U} / \mathrm{L}$, GPT $57 \mathrm{U} / \mathrm{L}$, alkaline phosphatase $3.494 \mathrm{U} / \mathrm{L}, \mathrm{LDH} 3.863 \mathrm{U} / \mathrm{L}$, renal function, electrolytes and the rest of the values were normal. Peripheral blood smears showed a leukoerythroblastic reaction with $33 \%$ eritroblasts and many schistocytes. Direct and indirect Coombs test: negative. Bone scan showed multiple bone metastases in the whole spine, pelvis, ribs and calvaria. CT body scans showed density abnormality of the perianastomotic tissue suggestive of local tumor recurrence and diffuse bone metastasis. Up- 
per GI endoscopy, colonoscopy, mammography and abdominal ultrasound were normal. Bone marrow biopsy disclosed metastasis of a signet ring cell adenocarcinoma. Inmunohistochemical staining was positive for CA19.9, CEA, cytokeratins (AE1, pancK, 8,18,19) and negative for citokeratins AE3, CD45, CD20, CD30, ALK1, CD68, CA125, c-erb-2, estrogen receptor, progesterone receptor, bcl-2, p53. The Ki67 rate proliferation was low. PET scan was not available.

Therefore a diagnostic of metastatic signet cell carcinoma of probably gastric origin with paraneoplastic MAHA was established and the patient was treated with multiagent chemotherapy cisplatin $80 \mathrm{mg} / \mathrm{m}^{2}$ intravenous (iv) on day 1 and 5 -FU $1.000 \mathrm{mg} /\left(\mathrm{m}^{2}\right.$-day) continuous infusion on days 1-5, zoledronic acid and intensive blood and platelet transfusions. After the first cycle of chemotherapy, the vaginal bleeding and epistaxis stopped and the hemoglobin level stabilized ( $>8 \mathrm{~g} / \mathrm{dL})$ and platelet increased over $30.000 / \mu \mathrm{L}$. Six courses of chemotherapy were delivered and clinical and laboratory response was evident (haemoglobin $11 \mathrm{~g} / \mathrm{dL}$, WBC 3.900 with 54\% neutrophils, normal platelets, alkaline phosphatase 340 U/L,LDH 522 U/L). A bone scan and CT scan showed a partial response in the number and intensity of bone lesions. Chemotherapy was then stopped and the patient started a follow-up program in our service. Three months later, the bone metastases progressed and the patient was treated with antialgic radiotherapy over L4-L5 (total dose 20 Gy). She received second line treatment with FOLFIRI, four cycles were delivered with progression of disease. Third line multiagent chemotherapy DCF (docetaxel 75 $\mathrm{mg} / \mathrm{m}^{2}$ iv day 1 , cisplatin $75 \mathrm{mg} / \mathrm{m}^{2}$ iv day $1,5-\mathrm{FU} 750$ $\mathrm{mg} / \mathrm{m}^{2} /$ day continuous infusion on days $1-5$ ) with a $20 \%$ dose reduction was started. She received 4 cycles with excellent clinical, biochemical and radiological response. After the fifth cycle, the patient came to the emergency room with an evident progression of the disease with severe pain, grade IV anemia, leucopenia and thrombopenia and radiological progression of the disease. The patient finally died due to bleeding and hypovolemic shock nineteen months after diagnosis. Unfortunately autopsy was not performed.

\section{Discussion}

Chemotherapy is the only treatment that can control the cancer and the paraneoplastic syndrome in this clinical setting and should be started as soon as possible. Due to the clinical findings and the history of gastric cancer, we decided to treat the patient as relapse of gastric cancer. Several case reports have shown good responses to chemotherapy, although there is no evident standard of care first-line chemotherapy [2]. We decided to use a combination regimen of two drugs instead of a triplet due to the poor performance status of the patient and the better toxic profile of the doublet [8]. We avoided regimens with epirubicin and docetaxel because of the myelotoxicity of these drugs. An alternative approach is the combination of oxaliplatin and fluoropyrimidines that have shown in phase III clinical trials to be less toxic and at least as effective as the combinations with cisplatin $[9,10]$. Despite the extremely severe thrombocytopenia, this should not be considered a contraindication of chemotherapy. The good partial response to chemotherapy and the long term survival achieved with chemotherapy show chemotherapy should be considered in all patients in this setting despite a poor performance status or severe cytopenias.

Positron emission tomography (PET) scan is a useful diagnostic test in metastasis of unknown origin. PET is a useful procedure both to detect the primary tumor and to identify additional sites of metastatic disease. PET detects more sites of metastasis than other modalities, and in $20 \%$ to $40 \%$ of cases it discloses the site of the primary tumor [11]. Its exact role is yet to be defined because of a lack of prospective clinical trials comparing the performance of PET with conventional diagnostic test. Unfortunately, in this clinical case PET scan was not performed due to we lacked this technique at the time of the patient was diagnosed.

Gastric cancer usually relapses in the first three years after surgery [12], however similar clinical cases have been reported with long periods of time between the primary tumor and the recurrence [5,6]. Some authors have suggested the origin of the metastasis in dormant tumor cells in the bone marrow and lymph ducts of the gastric wall in spite of normal gastric mucosa [6]. Our clinical case may support this hypothesis, however it is unclear why tumor cells remain dormant for as long as 12 years and which mechanism let them grow.

\section{Conflict of Interest}

The authors declare that they have no conflict of interest relating to the publication of this manuscript.

\section{REFERENCES}

[1] M. C. Brain, J. V. Dacie and D. O. Hourihane, "Microangiopathic hemolytic anemia: the possible role of vascular lesions in pathogenesis," British Journal of Haematology,; Vol. 8, 1962, pp. 358-374.

[2] K. H. Antman, A. T. Skarin, R. J. Mayer, H. K. Hargreaves and G. P. Canellos, "Microangiophatic Haemolytic Anemia and Cancer: A Review," Medicine, Baltimore, Vol. 58, 1979, pp. 377-384.

[3] H. T. Arkenau, O. Mussig, T. Buhr; H. H. Jend and R. Porschen, "Microangiopathic Hemolytic Anemia (MAHA) as Paraneoplastic Syndrome in Metastasized Signet Ring Cell Carcinomas: Case Reports and Review of the Literature," Z Gastroenterol, Vol. 43, 2005, pp. 719-722.

[4] F. Ozkalemkas, R. Ali, V. Ozkocaman, T. Ozcelik, U. Ozan, H. Ozturk, E. Kurt, T. Evrensel, O. Yerci and A. 
Tunali, "The Bone Marrow Aspirate and Biopsy in the Diagnosis of Unsuspected Nonhematologic Malignancy: A Clinical Study of 19 Cases," BMC Cancer, Vol. 5, 2005, p. 144.

[5] T. Kanou, Y. Nosou, K. Yoshinaka, E. Yanagawa, M. Niimoto, T. Hattori, K. Miura and J. Kuramoto, "Microangiopathic Hemolytic Anemia Associated with Gastric Cancer," Gan No Rinsho, Vol. 32, 1986, pp. 1029-1034.

[6] R. Takeuchi, M. Kuto, N. Katayama, N. Kamio, M. Tsuda, T. Nagano, M. Tomeoku, H. Wada, S. Murashima, K. Deguchi, et al., "Carcinomatosis Associated with Microangiopathic Hemolytic Anemia and Disseminated Intravascular Coagulation: 12 Years after Gastrectomy for Gastric Adenocarcinoma," Rinsho Ketsueki, Vol. 24, 1983, pp. 1423-1429.

[7] I. Mizuno, O. Izeki, S. Nakahara, K. Kawamoto, T. Onga, H. Matsuoka, T. Sugimoto, T. Matsui, H. Itoh, K. Chihara, "Disseminated carcinomatosis of the bone marrow occurring 11 years after subtotal gastrectomy for gastric cancer," Rinsho Ketsueki, Vol. 39, 1998, pp. 670-675.

[8] E. Van Cutsem, V. M. Moiseyenko, S. Tjulandin, A. Majlis, M. Constenla, C. Boni, A. Rodrigues, M. Fodor, Y. Chao, E. Voznyi, M. L. Risse, J. A. Ajani, et al., "Phase III Study of Docetaxel and Cisplatin Plus Fluorouracil Compared with Cisplatin and Fluorouracil as First-Line Therapy for Advanced Gastric Cancer: A Report of the V325 Study Group," Journal of Clinical Oncology, Vol.
24, 2006, pp. 4991-4997.

[9] S. E. Al-Batran, J. T. Hartmann, S. Probst, H. Schmalenberg, S. Hollerbach, R. Hofheinz, V. Rethwisch, G. Seipelt, N. Homann, G. Wilhelm, G. Schuch, J. Stoehlmacher, H. G. Derigs, S. Hegewisch-Becker, J. Grossmann, C. Pauligk, A. Atmaca, C. Bokemeyer, A. Knuth and E. Jäger, "Arbeitsgemeinschaft Internistische Onkologie. Phase III Trial in Metastatic Gastroesophageal Adeno- carcinoma with Fluorouracil, Leuco-Vorin Plus Either Oxaliplatin or Cisplatin: A Study of the Arbeitsgeme- inschaft Internistische Onkologie," Journal of Clinical Oncology, Vol. 26, 2008, pp. 1435-1442.

[10] D. Cunningham, N. Starling, S. Rao, T. Iveson, M. Nicolson, F. Coxon, G. Middleton, F. Daniel, J. Oates and A. R. Norman, "Upper Gastrointestinal Clinical Studies Group of the National Cancer Research Institute of the United Kingdom. Capecitabine and Oxaliplatin for Advanced Esophagogastric Cancer," New England Journal of Medicine, Vol. 358, 2008, pp. 36-46.

[11] D. A. Podoloff, "PET/CT and Occult Primary Tumors," Journal of the National Comprehensive Cancer Network; Vol. 7, 2009, pp. 239-244.

[12] J. S. Macdonald, S. R. Smalley, J. Benedetti, et al., "Chemoradiotherapy after Surgery Compared with Surgery Alone for Adenocarcinoma of the Stomach or Gastroesophageal Junction," New England Journal of Medicine, Vol. 345, No. 10, 2001, pp. 725-730. 